very existence of the observable Universe depends upon the spontaneous manifestation of asymmetry, the phenomenon physicists call 'broken symmetry'. Close focuses, at first, on two discrete broken symmetries: the universal 'handedness' of life - its left-right asymmetry - and the cosmic preference for matter over antimatter. In the final chapters, he goes on to expound the broken continuous symmetry that is behind the unification of weak and electromagnetic interactions.

It is hard to judge how accessible the layman will find tutorial explication of the sort contained in this book. For instance, it's not clear to me why Stephen Hawking's writing seems to be comprehensible, or at least acceptable, to the layman; I would judge Close to be much more accessible. So, to my limited sense of these things, this should be a book that the interested layman will enjoy.

But here's the rub. As I read on, I became increasingly uncomfortable, and particularly so in the final chapters. The first rule of popular writing about science should parallel the well-known law of medicine: 'First, do no harm', which in this context translates into, 'First, get the story straight'.

There are three noteworthy failures to do this. Two major ones may derive from the praiseworthy motivation of making the presentation easier or more dramatic, but as the 'first rule' points out, the baby should not go out with the bath water.

In a book focusing, as this does, on symmetry, it seems misleading not to explain the fundamental principle that all interaction follows from symmetry: the gauge principle of London and Weyl, modelled on and foreshadowed by Einstein's derivation of gravity from general relativity (Einstein seems to be at the root of everything). The beautiful idea that every continuous symmetry implies a conservation law, and an accompanying interaction between the conserved charges, determines the structure of all of the interactions of physics. It is not appropriate to try to approach advanced topics such as electroweak unification and supersymmetry without this foundation block.

Second, there is little resemblance between the real story of how broken symmetry entered particle physics - and of the 'Higgs phenomenon' as the generator of mass - and the rather dramatic little myth created by Close around these events. One supposes that the classic stories of discovery, some of which Close retells elsewhere in the book, may traditionally be somewhat retouched to spice up the exposition; but that is no excuse for making up a new myth out of whole cloth.

The idea of broken symmetry as a way of generating mass is universally credited to Yoichiro Nambu, who was inspired in 1959-60 by the then new BCS theory of superconductivity. The Higgs phenomenon was, in fact, discovered in that theory by me

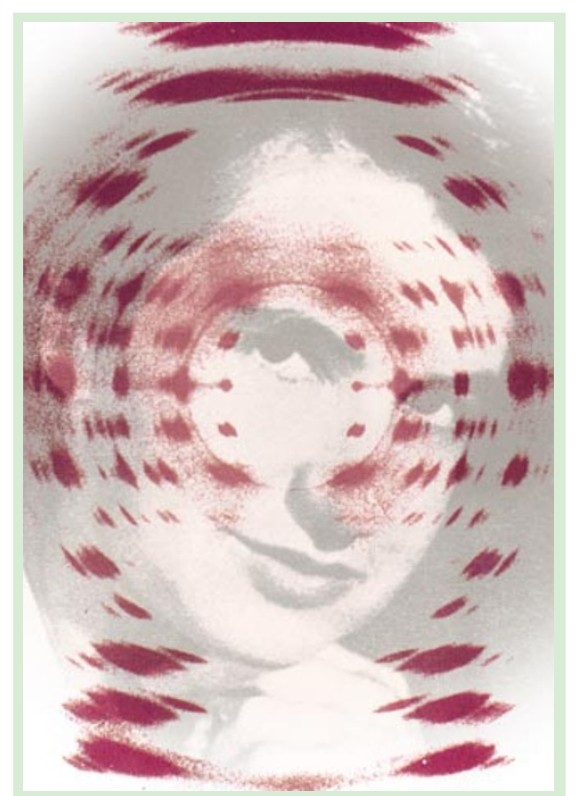

\section{A double-take on nature's helix}

The striking symmetry of the $\mathrm{X}$-ray crystallograph of DNA prepared by Rosalind Franklin was one of the last clues that led Watson and Crick to deduce the left-handed double-helical structure of DNA. From Nature's Connections: An Exploration of Natural History by Nicola McGirr (Natural History Museum, £12.95).

and applied to particle physics in 1963, a year before Higgs' "great inspiration". The major portion of the credit has correctly gone to Steve Weinberg, Abdus Salam, Sheldon Glashow and John Ward (recently deceased), who, around 1967, put all these ideas together in the right way. (A revelatory hint that Close has not understood the mechanics of the Goldstone-Higgs process is the use of the false analogy to ferromagnetism; unlike the ferromagnetic moment, the Higgs field is not a constant of the motion!) Higgs, whom Close measures up for a Nobel, was a rather minor player, whose contribution was parallel to that of Robert Brout and François Englert.

A precedent for Close's emphasis on the Higgs particle, if not on Peter Higgs himself, is the older attempt to cover some of the same material, Leon Lederman's The God Particle (1990), in which the eponymous particle is indeed the Higgson. Close will leave the reader much less confused than will Lederman, and is wonderfully frugal with irrelevant detail; but the account of the physics has similar weaknesses.

Finally, while the attention of a few biologists has been caught by the physicists' natural conjecture that the handedness of life is somehow affected by that of the weak interactions, I sense that most thinkers on evolution feel that life would be much harder to understand if it were not universally chiral.

I personally think it a great pity that Close did not tell the story of broken symmetry as it really happened, because it is a heartening story of one of those rare periods when the fragmentation of theoretical physics into condensed-matter, nuclear and particle branches was temporarily healed and we were all consciously working together in exploring the many quantum consequences of the idea of broken symmetry.

These consequences are as far-reaching and as intellectually stimulating in condensed matter as in particle physics, and in not discussing them Close reveals a definite bias in favour of the 'clean machines' of particle physics as opposed to the mundane complications of condensed matter. Not surprisingly, the book ends with a paean in praise of the magnificent (and magnificently expensive) particle physics machinery at CERN, in happy anticipation of a continued flow of exciting results. One must, of course, share his hope, if not necessarily his optimism. But I regret very deeply the missed opportunity to demonstrate to laymen the unity of the physics enterprise, and Close's treatment of the rest of physics as a poor relation of particle physics, of simply historicalvalue.

P. W. Anderson is in the Department of Physics, Princeton University, PO Box 708, Princeton, New Jersey 08544-0708, USA.

\section{Portrait of an élite world}

\section{Cavendish: The Experimental Life}

by Christa Jungnickel and

Russell McCormmach

Bucknell University Press: 1999. 814 pp.

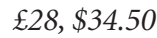

\section{John Gascoigne}

The name 'Cavendish' immediately calls to mind the Cambridge laboratory that has produced more Nobel prizewinners than any other scientific institution. There is a link between the laboratory and the lateeighteenth-century Henry Cavendish who is the subject of this definitive biography, but it is an indirect one. When, in 1874, the Duke of Devonshire displayed his aristocratic munificence in founding the laboratory, he chose to commemorate the scientific achievements of his distant relative.

It was an appropriate memorial, as family tradition played an important part in shaping Henry Cavendish's scientific endeavours. The biography brings this aspect out well by taking as its subject not only Henry but also his little-known father, Charles. As the grandson of two dukes 
(Devonshire and Kent), young Henry had no need to trouble himself with earning a living, and as he grew older he grew richer, thanks to family legacies, a frugal lifestyle and secure investments. He became, as the French physicist Jean Biot put it, " the wisest of the rich and the richest of the wise".

But he came from an aristocratic élite whose long survival owed much to the fact that they generally understood that privilege had to be balanced by some form of service. The most common form taken by such civic duty was to enter politics, as Henry's father had done. But such a course was closed to Henry by a chronic shyness that led to him literally fleeing if he was button-holed at a social gathering and by a morbid fear of female company.

So, with paternal blessing, Henry turned to science and, in particular, to experimental science of the kind cultivated by his father. He also continued his father's tradition of service to the Royal Society and other learned institutions such as the British Museum. Indeed, it is one of the paradoxes of Cavendish's career that such an extremely introverted character should have been a good committee man. Not only did he serve the Royal Society in various capacities, but he was also a manager of the Royal Institution and a member of the Royal Society of Arts and the Society of Antiquaries. In an age when the characteristic institution of British learned society was the club, the seemingly unclubbable Cavendish was a ubiquitous presence - although one that might rapidly disappear if he was singled out for attention.

Cavendish's chronic shyness was evident, too, in his marked reluctance to publish unless he was totally satisfied with the results - a rare event. The consequence was that, over a lifetime devoted to experimentation (since the bachelor had few domestic distractions), he published fewer than 20 papers. The world, then, saw only some outworks of a majestic edifice that covered most of science as it was then understood. What gave his work unity was his devotion to continuing the Newtonian enterprise of attempting to understand the world in terms of attractive and repulsive forces. It underlay his pioneering work in electricity, which demonstrated both the insights and limitations of the Newtonian concept of force when applied to electrical activity. Although he did publish two papers in this area, largely based on the analogy between the fluid-like behaviour of air and electricity, much of his work, such as his laws of electrical attraction and repulsion, were virtually stillborn as they were never published.

The Newtonian world-view also informed his elegant (and published) 1798 experiment using lead weights on a torsion bar to estimate the strength of the Earth's gravitational attraction which, in turn,

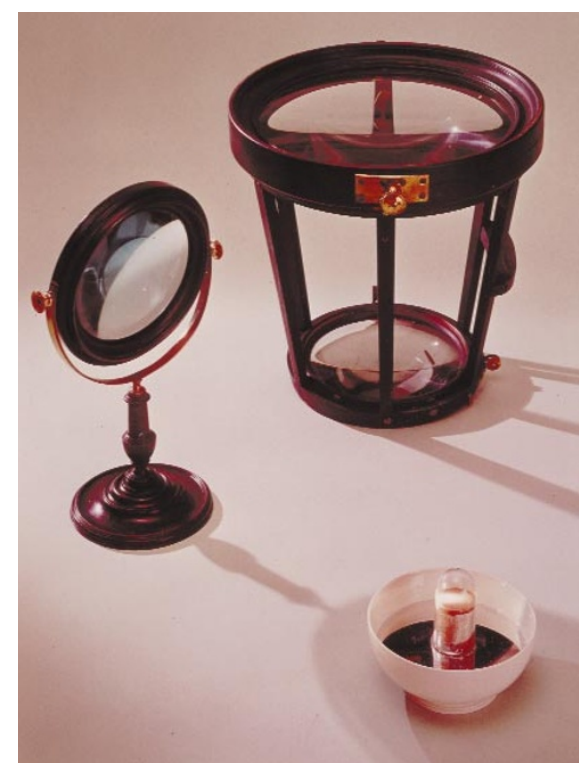

Tools of his trade: lenses used by Cavendish, who viewed science as a form of escape.

enabled Cavendish to calculate the Earth's density and weight.

Cavendish's work was also informed by the view that, to some degree, all natural phenomena could be explained in terms of the behaviour of fluids. This was evident both in his electrical experiments and in his pioneering work on what he called 'factitious airs', that is, forms of air that can be released from other bodies - of these, the two most notable were 'inflammable air' (hydrogen) and 'fixed air' (carbon dioxide). The very fact that he distinguished between such forms of air was an indication of the withering of the traditional view that the four elements earth, air, fire and water were the irreducible building-blocks of the world. This ancient understanding of the elements was to be further undermined by Cavendish's experiments in 1784 demonstrating that water was a compound of two airs, 'inflammable' and 'common'. Fortunately, he was sufficiently satisfied with his conclusions to publish them and they were instrumental in prompting
Antoine Lavoisier to develop a totally new understanding of the concept of an element.

In this lengthy work, the authors clearly and systematically describe Cavendish's scientific achievements as well as providing a portrait of the élite world in which he and his father developed their scientific interests. This new edition also publishes Cavendish's surviving scientific correspondence.

After such Herculean labours, it is natural enough for the authors to place their subject on a very high pedestal. Their view that Cavendish "was the preeminent mathematical and experimental scientist in Britain in the century and a half between Newton and Thompson and Maxwell" may be defended, although others might yield such laurels to Thomas Young or Michael Faraday. More contentious is their claim that "Cavendish is one of the greatest scientists ever, as he is one of the most unusual personalities of science". That claim is perhaps based on an assessment of the whole corpus of his work, with insufficient allowance for the fact that scientific eminence can generally accrue only from published work. For the aristocratic Henry Cavendish, spared the financial pressures to turn knowledge into career capital, publication may have appeared an optional and occasional interruption. However, science is, by its nature, a social activity which depends on the sharing of knowledge. The reclusive Cavendish made a remarkable contribution, but his view of science as a form of escape from the madding crowd limited his influence and his ultimate place in the scientific pantheon.

John Gascoigne is in the School of History, Faculty of Arts and Social Sciences, University of New South Wales, Sydney 2052, Australia.

\section{New in paperback}

\section{The River: A Journey Back} to the Source of HIV and AIDS by Edward Hooper

\section{Penguin, £10.99}

"The River is, in many ways, superb. It is scholarly, thoroughly researched, well (if densely) written and deserves, indeed demands to be taken seriously ... His description of the early days of the African and Western AIDS epidemics is marvellous, but it is his support for the OPV-HIV hypothesis that will attract most attention ... My biggest concern over this book is that it could reinforce public distrust of science and scientists. It is a dangerous policy to hammer science for unproven — and probably unprovable - events." John P. Moore, Nature 401, 325-326 (1999)

\section{Evolutionary Wars:}

A Three-Billion-Year Arms Race

by Charles Kingsley Levy

W. H. Freeman, $£ 10.95, \$ 16.95$

Citizen Science: A Study of People, Expertise and Sustainable Development by Alan Irwin

Routledge, £16.99, \$24.99 